\title{
Uma experiência de uso de Sistemas de Resposta à Audiência em atividade de educação não formal
}

Robertino Mendes Santiago Jr - Universidade Federal do Paraná - robertino@ufpr.br Carlos Roberto Beleti Junior - Universidade Federal do Paraná - carlosbeleti@ufpr.br Maytê Gouvêa Coleto Bezerra - Universidade Federal do Paraná - mayte@ufpr.br Alexandre Prusch Züge - Universidade Federal do Paraná - alexandrezuge@ufpr.br

Resumo: O uso da tecnologia, na Educação, tem crescido, contribuindo para experiências mais atraentes e para aprendizagens significativas. Um recurso destacado são os Sistemas de Resposta à Audiência (SRA), que permitem encorajar a participação, recolher e processar as informações e viabilizar feedback imediato. Aqui, relatamos o uso do SRA em uma ação de Educação não formal sobre Arquitetura de Computadores (AC), com 160 estudantes dos anos finais, do Ensino Fundamental, antes e depois de intervenções que apresentavam componentes de computadores. O SRA, além da relação com o tema da AC, foi de fácil uso, permitiu agilidade no tratamento dos dados e esclarecimento de dúvidas. Assim, o SRA evidenciou virtudes e fragilidades, incrementando a ação e orientando ajustes que a melhorarão em novas oportunidades.

Palavras-chave: arquitetura de computadores, educação não formal, sistemas de resposta à audiência.

\section{An experience of using audience response systems in non-formal education activity}

Abstract: The use of technology in Education has grown, contributing to more attractive experiences and significant learning. Audience response systems (ARS) are outstanding resources, which allow to encourage participation, collect and process information and provide immediate feedback. In this paper, we report the use of an ARS in a non-formal education activity on Computer Architecture (CA), with 160 students from the final years of Elementary School, before and after interventions that featured computer components. The ARS, in addition to the relationship with the theme of CA, was easy to use, and allowed agility in the treatment of data and in clarification of doubts. Thus, the ARS showed virtues and weaknesses, improving the activity in progress and guiding adjustments that will improve it in new opportunities.

Keywords: computer architecture, non-formal education, audience response systems.

\section{Introdução}

Os avanços tecnológicos, das últimas décadas, possibilitaram que os equipamentos computacionais fossem acolhidos ou reivindicados por diversos contextos. No educacional, esses equipamentos podem ser utilizados para atrair a atenção dos(as) estudantes e atuarem como ferramentas facilitadoras no processo de ensino e de aprendizagem, em diferentes áreas do conhecimento, tanto em escolas como em universidades (Brito, 2019; Medeiros et al., 2012).

Uma das tecnologias que pode ser incorporada ao contexto educativo, presencial ou a distância, em ambientes formais ou não, é o Sistema de Resposta à Audiência (SRA, do inglês, Audience Response Systems), também conhecido como clickers. Tal sistema incorpora "tanto hardware, quanto software que permitem estudantes [...] responderem a questões utilizando um aparelho de controle remoto" (Medeiros et al., 2012, p. 2). 
Ao automatizar a avaliação e a própria sistematização das respostas, os SRA permitem que educadores tenham acesso imediato ao desempenho de estudantes e que repercutam, em tempo real, os resultados de modo que os(as) próprios(as) participantes possam, também, reconhecer seu desempenho e do grupo (Medeiros et al., 2012). A partir de uma primeira análise sobre os processos de resolução e categorização das respostas, educadores podem mediar os processos de aprendizagem envolvidos (Sousa, 2013).

Esses recursos, somados à possibilidade de anonimato, fazem com que os SRA contribuam com o engajamento e com a motivação dos(as) estudantes para com o processo educacional. Mesmo os(as) estudantes reticentes ou receosos em se expor são acolhidos pela dinâmica e ficam mais acessíveis aos(às) profissionais da educação. Nesse sentido, conforme sugerem Goldstein e Wallis (2015), os SRA constituem uma tecnologia capaz de dinamizar e aumentar a eficácia do processo educativo.

Ante ao exposto, este artigo relata o uso de SRA como ferramenta de apoio para avaliar e validar a efetividade das atividades educativas, realizadas em ambiente de Educação não formal, na apropriação de conceitos de Arquitetura de Computadores (AC), para adolescentes, no contexto de ações de um projeto de extensão universitária.

Sobretudo, defendemos que é válido avaliar a efetividade de atividades educativas realizadas em ambientes de Educação não formal. Mesmo que, nesses espaços e nessas ações, conforme ensina Gadotti (2005), a duração das intervenções seja variável e não haja necessidade da existência de um sistema sequencial e hierárquico de progressão, os(as) educadores(as) também podem desejar mensurar o alcance de seus objetivos educativos (considerar os resultados alcançados e, com isso, analisar as práticas desempenhadas). Ou seja, ainda que não haja hierarquização de processos institucionalizados de aprendizagem, os ambientes e ações educativas não formais, por sua intencionalidade educativa, não prescindem de apreciar seus resultados (Gohn, 2010).

\section{Trabalhos relacionados}

Autores como Silva e Correia (2014) e Sanches et al. (2014), defendem que a inserção das tecnologias, nos ambientes educativos, tem potencial para tornar tanto a experiência educativa mais atrativa e significativa para quem aprende, como também mais prazerosa e dinâmica para quem ensina, e que, de modo geral, pode contribuir para $\mathrm{o}$ incremento da qualidade dos processos de ensino e de aprendizagem.

Conforme apontam Beleti Junior et al. (2020), Sistemas de Resposta à Audiência não são de uso exclusivo de ambientes formais de educação, podendo ser utilizados em ambientes e iniciativas de educação não formal. Essa compreensão encontra lugar nas ações empreendidas no projeto de extensão universitária em questão.

Entretanto, destaca-se que não localizamos, na literatura, iniciativas com o mesmo propósito. Desse modo, na sequência, apresentamos trabalhos que fazem uso dos SRA, em ambientes formais e em níveis de escolaridade distintos da experiência proposta pelo trabalho em tela, mas que, apesar disso, nos permitem refletir e discutir a nossa experiência.

De início, esclarecemos que, na literatura revisada, encontramos artigos que fazem uso de outros termos como sinônimo de SRA, tais como: sistemas de desempenho em sala de aula, sistemas de resposta pessoal, sistemas de comunicação em sala de aula, sistemas de resposta eletrônica, sistemas de votação eletrônica, sistemas de votação ou sistemas de clicker (Aljaloud et al., 2015).

De modo geral, as pesquisas têm descrito o uso de SRA como fator central na melhora da atenção, no aprendizado, na participação e no entusiasmo, durante as 
atividades realizadas (Cartwright e Fabian, 2017; Premkumar, 2016; Aljaloud et al., 2015), com comparações entre desempenho do(a) estudante com e sem uso dos SRA (Dębiec, 2017; Caldwell, 2007; Martyn, 2007), inclusive, com a realização de análises entre grupos de controle e experimental (Barrio et al., 2015; Sousa, 2013); além de pesquisas com foco na identificação de desafios inerentes ao uso de SRA (Aljaloud et al., 2015; Sousa, 2013).

Encontramos, ainda, trabalhos que enfatizam a importância do emprego das tecnologias no contexto educacional, inclusive, desenvolvendo, analisando e comparando diferentes sistemas de resposta à audiência (Sousa, 2013; Medeiros et al., 2012), ou, mesmo, ilustrando os tipos de clickers existentes e software utilizados durantes suas atividades (Premkumar, 2016; Barrio et al., 2015; Sousa, 2013; Medeiros et al., 2012).

Quanto ao ambiente de ensino, em que tal tecnologia é empregada, a ampla maioria dos estudos relaciona-se a práticas no ensino formal, em nível superior (Cartwright e Fabian, 2017; Dębiec, 2017; Premkumar, 2016; Aljaloud et al., 2015; Heaslip et al., 2014; Sousa, 2013; Caldwell, 2007). Nesses ambientes, trabalhos, ainda, sinalizam o uso conjunto dos SRA com outras abordagens de ensino, tal como a gamificação (Barrio et al., 2015), métodos de aprendizado ativo (Dębiec, 2017) e a instrução por pares (Caldwell, 2007).

As áreas de conhecimento, em que podem ser empregados os SRA, são diversas mas, grande parte de trabalhos concentra-se em cursos da área da Computação (Dębiec, 2017; Premkumar, 2016; Sousa, 2013; Martyn, 2007), em mais de uma área na mesma pesquisa - Redes de Computadores e Socioestatística (Barrio et al., 2015) - Biologia e Matemática (Caldwell, 2007), entre outras - como Criminologia (Cartwright e Fabian, 2017), Contabilidade, Gestão, Empreendedorismo, Negócios Equinos e Artes (Heaslip et al., 2014).

\section{Metodologia}

Possuir conhecimentos básicos sobre AC é de importância global, pois a tecnologia derivada da computação está por toda parte. É por meio dela que diversas atividades, que outrora exigiam mão-de-obra humana, foram automatizadas e serviços foram agilizados e facilitados, enquanto a oferta de vagas de trabalho, em ocupações especializadas, no ramo da informática e das comunicações, segue aumentando (Moraes e Kohn, 2007).

O projeto de extensão "Por dentro do computador"”, da Universidade Federal do Paraná - Campus Jandaia do Sul, desenvolve, desde 2014, atividades de popularização de ciência e tecnologia, sobretudo acerca de AC, buscando atingir públicos variados da região Norte Central do Paraná, por meio de intervenções em ambientes de educação não formal. Atualmente, o projeto é chancelado pela Sociedade Brasileira de Computação (SBC).

Nesse contexto, o SRA tem sido utilizado como forma de verificar a efetividade das intervenções realizadas e, com isso, retroalimentar o desenvolvimento das atividades. A partir das respostas dos(as) participantes, são identificadas as virtudes e, sobretudo, os pontos frágeis a serem melhorados durante cada proposição realizada.

A experiência que nos serve à reflexão, aqui apresentada, é a da utilização do SRA, durante uma intervenção educativa, cuja metodologia é baseada no trabalho de Beleti Junior et al. (2020), realizada pelo projeto de extensão supracitado, com 160

\footnotetext{
${ }^{1}$ Página institucional do projeto: http://www.jandaiadosul.ufpr.br/extensao/por-dentro-do-computador/ V. $18 \mathrm{~N}^{\mathrm{o}} 1$, julho, 2020 RENOTE DOI:
} 
estudantes dos anos finais, do ensino fundamental, durante uma mostra científica, promovida em uma escola estadual paranaense, em 2019.

A atividade realizada foi organizada a partir de uma adaptação da abordagem conhecida como Rotação por Estações. Segundo Horn e Staker (2015), tal modelo sugere que os(as) estudantes se desloquem por estações de aprendizagem, seguindo uma programação fixa ou a critério do(a) educador(a) mediador(a). Em nossa proposta, as estações definidas foram (Figura 1): a) estação do conhecimento; b) estação dos componentes do computador; e c) estação do diorama.

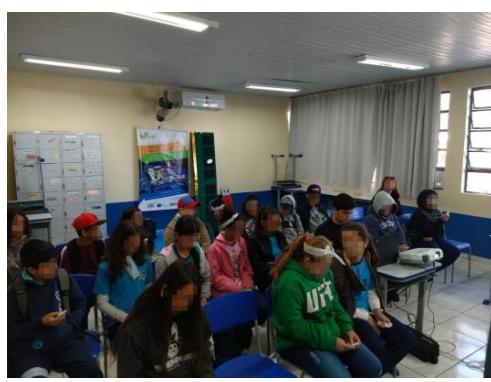

(a)

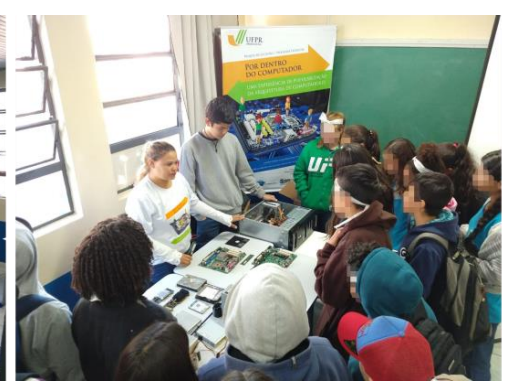

(b)

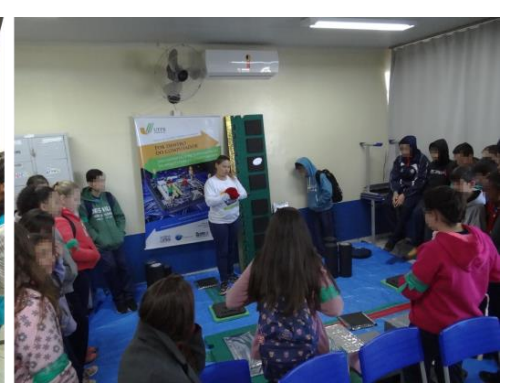

(c)

Figura 1 - Estações utilizadas na intervenção. Fonte: Autoria própria.

A estação do conhecimento (Figura 1a) objetivava, primeiramente, levantar dados acerca do conhecimento prévio dos(as) participantes a respeito da AC e, também, aqueles adquiridos em decorrência da participação na atividade, sendo visitada tanto no início, como ao final da rotação. Foi, nessa estação, portanto, que os(as) participantes utilizaram o SRA para responderem às questões propostas.

Já a estação dos componentes do computador (Figura 1b) visava apresentar, através da exposição de um "computador aberto", seus principais componentes, sendo cada um explicado individualmente, demonstrando, também, sua importância geral no funcionamento da máquina.

Por sua vez, a terceira estação, a estação do diorama (Figura 1c), era uma representação, em escala aumentada (em 15 vezes), de um computador, onde os(as) participantes podiam, literalmente, "caminhar por dentro de um computador".

O modelo de SRA utilizado, neste trabalho, foi o TurningPoint $L C D$, em combinação com o software TurningPoint Desktop. Nesse caso, um conjunto de aparelhos eletrônicos (cartões eletrônicos de resposta, cartão eletrônico do apresentador e dispositivo receptor de sinal) se comunicando por sinais de radiofrequência. O sistema inclui um software capaz de transformar os sinais recebidos em dados pertinentes, os quais são armazenados ao objeto de avaliação, permitindo que os(as) participantes respondam perguntas em tempo real e que tais respostas sejam coletadas com a identificação dos(as) respondentes ou, ainda, de forma anônima, por meio dos cartões eletrônicos de respostas.

O sistema permite aos(às) educadores(as) produzir apresentações com tipos variados de respostas a uma determinada pergunta - de múltipla escolha, verdadeirofalso, escala Likert, entre outras - as quais os(as) estudantes são convidados a responder utilizando o cartão eletrônico de resposta, como o exibido na Figura 2a.

Após o(a) apresentador(a) perguntar e os(as) participantes responderem, os resultados podem aparecer em uma apresentação de slides, caso seja necessário, tal qual na Figura 2b, que exibe o conjunto de alternativas possíveis e o resultado das respostas dos(as) participantes, em formato de gráfico, com destaque (em verde) para a alternativa correta. 


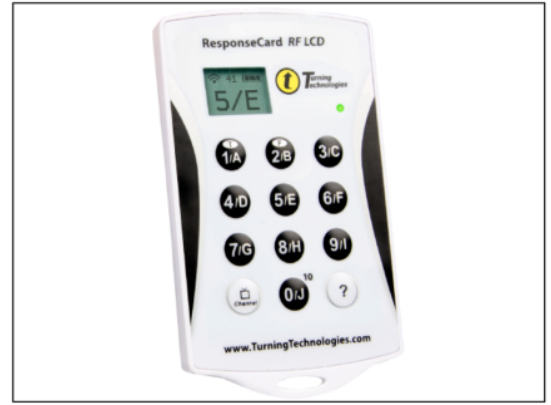

(a)

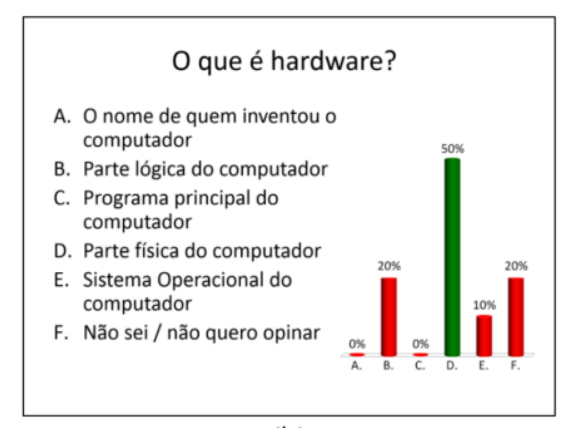

(b)

Figura 2 - SRA - a) cartão eletrônico de resposta. b) Feedback das respostas. Fonte: a) Site do Fabricante ${ }^{2}$. b) Autoria própria.

A duração total da intervenção foi de, aproximadamente, 30 minutos, sendo destinados 10 minutos para cada estação. Cabe ressaltar que a composição do tempo da estação do conhecimento foi de 5 minutos, no início da intervenção, e 5 minutos, ao final. A ordem em que os(as) participantes transitaram pelas estações pode ser observada na Figura 3.

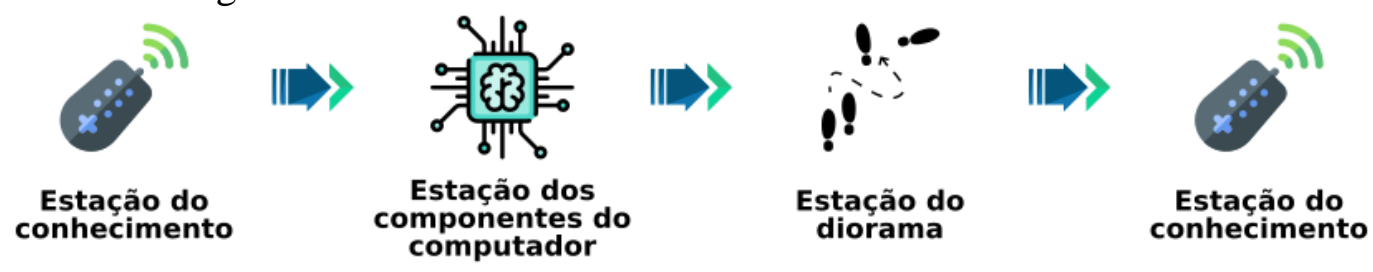

Figura 3 - Ordem das estações. Fonte: Autoria própria.

\section{Desenvolvimento}

Primeiramente, é preciso destacar que, sendo o SRA uma tecnologia nova para a maioria dos(as) participantes, houve um momento prévio de explicação sobre a maneira de utilizá-lo. Assim, antes de iniciarmos a atividade com os clickers, no pré-teste, o educador comentava sobre seu funcionamento geral, explicando sobre as possibilidades de resposta, necessidade de clicar em alguma alternativa etc. Dentre as estratégias de familiarização dos(as) participantes com o recurso, aludimos ao uso em um programa televisivo, de amplo conhecimento, que colhia, ao vivo, a nota atribuída por espectadores(as) da plateia às apresentações que se davam no palco. A possibilidade de lidar com o mesmo recurso tecnológico, utilizado na televisão, parecia empolgar bastante os(as) adolescentes.

Conforme mencionado, o SRA foi utilizado para avaliar o conhecimento prévio dos(as) estudantes participantes da ação educativa (pré-teste) e aqueles adquiridos ou consolidados a partir da própria intervenção (pós-teste). Desta forma, considerando a adaptação do modelo de Rotação por Estações, utilizado na metodologia, realizou-se, por meio da estação do conhecimento, a aplicação desses dois momentos.

Em ambas as avaliações, utilizamos um questionário que trazia sete perguntas, que abordavam conceitos essenciais das máquinas computacionais atuais (smartphones, tablets, notebooks), como, por exemplo, sobre processadores, processamento gráfico, memória primária e secundária, entre outros. Vale ressaltar que esses conceitos seriam apresentados aos(às) participantes nas demais estações.

As questões eram de múltiplas escolhas (com respostas identificadas de A a F), sendo apenas uma correta, incluindo, ainda, uma resposta descrita como "Não sei/não quero opinar". A inclusão de tal alternativa surgiu de experiências anteriores, nas quais

2 Disponível em: https://www.turningtechnologies.com/lcd/. Acesso em: 01/04/2020. V. $18 \mathrm{~N}^{\mathrm{o}} 1$, julho, 2020 
percebemos que havia uma distribuição muito ampla das respostas, na fase do pré-teste, que poderiam indicar a ocorrência de "chutes" por parte dos(as) participantes, ou seja, frente à pressão por responder e sem o necessário conhecimento para tal, o(a) participante se via obrigado(a) a indicar uma alternativa qualquer. Com a atual composição de alternativas, que comporta essa resposta, os(as) participantes, mesmo com dúvidas, não se sentem desmotivados(as) a continuar respondendo; pelo contrário, o lugar do "não saber" passa a ser ressignificado, como uma forma de resposta possível e aceitável, dando lugar para o "não saber" como algo positivo que mobiliza a curiosidade para o aprendizado e não o obstaculiza.

Dessa forma, durante o pré-teste, os(as) participantes foram convidados(as) a responderem, com base no conhecimento prévio, sobre os conceitos computacionais e, caso não soubessem, foram motivados pelos(as) mediadores(as) (estudantes de graduação, voluntários(as) e bolsistas do projeto) a responderem "Não sei/não quero opinar". $\mathrm{Na}$ aplicação do pós-teste, os(as) mediadores(as) motivaram os(as) participantes a realizarem uma reflexão sobre a atividade realizada, com o objetivo dos(as) participantes recordarem os conceitos apresentados no decorrer da atividade.

Ressalta-se que, apenas no pós-teste, ou seja, ao fim de toda a rotação pelas estações e retorno à estação do conhecimento, a resposta correta foi apresentada aos(às) participantes, juntamente, com o desempenho da turma na questão, de modo semelhante ao ilustrado na Figura $2 b$.

Para o bom desenvolvimento e aproveitamento da intervenção pelos(as) participantes, os(as) adolescentes foram divididos(as) pela própria escola em dez grupos menores, de idade e anos variados (do $6^{\circ}$ ao $9^{\circ}$ ), com quantidades variadas de integrantes, sendo: um grupo com 9, quatro grupos com 14, um grupo com 17, um grupo com 18, um grupo com 19, um grupo com 20 e outro grupo com 21 , totalizando 160 participantes.

\section{Resultados e Discussão}

O primeiro apontamento a ser realizado, diz respeito a adesão dos(as) adolescente em participarem dos dois momentos na estação do conhecimento, mediados pelo SRA. Sobre isso, os números mostraram, em ambos, a participação maciça na dinâmica apresentada, salvo prováveis erros de uso dos clickers, não registrando uma ou outra resposta, de modo que nos dez grupos e nas sete questões, contabilizamos uma variação entre 154 e 159 respondentes, no total.

Outra apreciação recai sobre a distribuição das respostas dos(as) participantes no primeiro momento correspondente ao pré-teste, conforme Figura 4.

\section{Pré-teste}

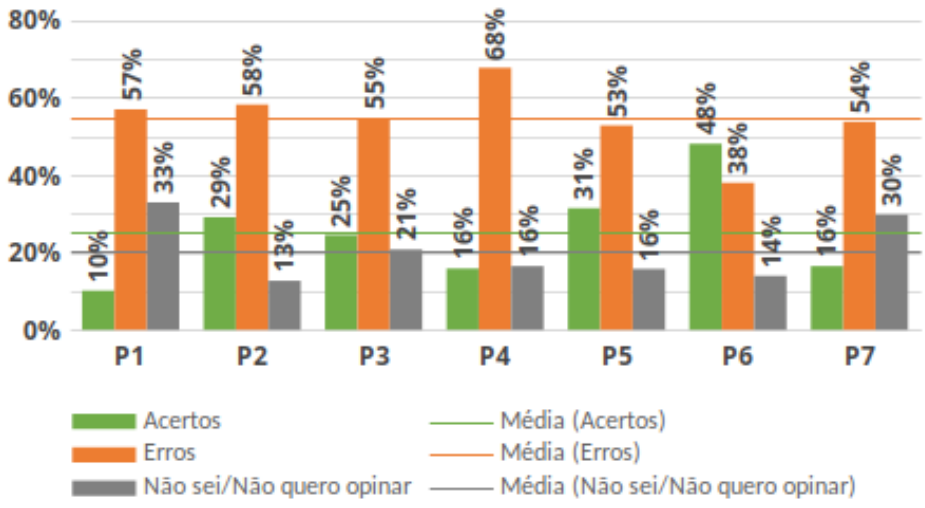

Figura 4 - Distribuição das respostas e a média de acertos, de erros e da alternativa "não sei/não quero opinar", no pré-teste. Fonte: Autoria própria. 
Ao avaliarmos o conhecimento prévio aferido dos(as) participantes, aqui, percebemos uma baixa taxa de acerto $(25 \%)$, em contraste a uma alta taxa de erros (55\%), em média. Ainda, ao observarmos a taxa de seleção da opção "Não sei/não quero opinar", temos que essa forma de participação foi significativa no conjunto do pré-teste (20\%), chegando, em algumas questões e grupos, a índices de até $33 \%$, o que reforçou a importância de sua existência dentre as alternativas.

Assim, reconhecemos, portanto, que o público participante, em sua maioria (75\%), mostrava-se confuso sobre o conteúdo de AC que seria apresentado, cometendo, ainda, bastantes equívocos, ou mesmo afirmando desconhecê-lo significativamente.

Quando comparamos o desempenho geral dos(as) participantes, nas duas etapas, pré-teste e pós-teste, ou seja, depois de passarem nas estações dos componentes e na do diorama, verificamos mudanças gerais das respostas, conforme se vê na Figura 5.

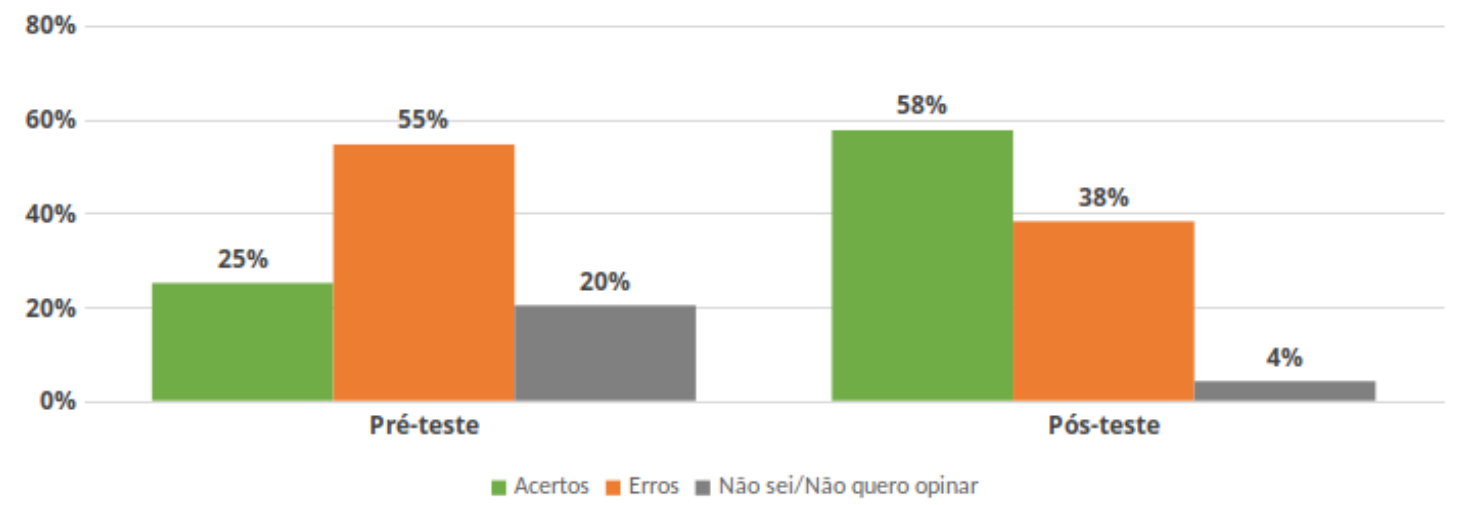

Figura 5 - Relação de acertos, de erros e de respostas "não sei/não quero opinar", obtidos na estação do conhecimento. Fonte: Autoria própria.

Assim, foi possível constatar uma melhora no percentual na taxa de acertos durante o pré-teste e o pós-teste. A média de acertos, no pré-teste, foi de $25,09 \%$, com desvio padrão de $12,72 \%$, e a média, no pós-teste, foi de $57,65 \%$, com desvio padrão de $13,35 \%$. Com um ganho de 32,5 pontos percentuais, tem-se uma melhoria de mais de $100 \%$ nas respostas corretas dos alunos e das alunas participantes, o que indicou uma tendência de aquisição de informação por parte desses(as) estudantes.

Além disso, comparando-se os percentuais da seleção da alternativa "não sei/não quero opinar", constatou-se uma diminuição de $80 \%$ em sua indicação. Ou seja, parece haver, por parte dos(as) participantes, uma sensação de "ganho" de conhecimento, que os permitiria, no segundo momento da avaliação, ousar uma resposta mais assertiva.

Ao nos debruçarmos sobre os resultados das questões, isoladamente, podemos constatar, conforme Figura 6, que a maioria das perguntas tiveram melhorias quanto ao aumento percentual, em média, de respostas corretas. A maior diferença, entre os resultados assertivos, foi na questão P7, na qual houve aumento de, aproximadamente, 54 pontos percentuais.

Como se verifica, no gráfico, a única pergunta em que foi observado decréscimo, no percentual de acertos, foi a P6, tendo, no pré-teste, aproximadamente, $48 \%$ de acertos e 39\%, no pós-teste, em média. A questão 6 abordava conceitos sobre dispositivos de entrada e de saída do computador. Durante o pós-teste, pelo fato do SRA apresentar o gráfico sobre os acertos e os erros, foi possível identificar que a maioria dos(as) participantes responderam erroneamente essa questão, além da possibilidade de conhecer quais das alternativas incorretas o público acreditava ser a certa. Dessa forma, os(as) educadores(as) que mediavam a intervenção, puderam, no mesmo momento, retomar os conceitos sobre esses dispositivos, explicando, novamente, aos(às) V. $18 \mathrm{~N}^{\mathrm{o}} 1$, julho, 2020 RENOTE DOI: 
participantes e corrigindo as incompreensões que ainda permaneciam, ou seja, serviu, por sua imediatez, ao implemento da intervenção em curso. Ademais, essa identificação possibilitou que a atividade fosse aprimorada para oportunidades futuras, sinalizandonos a necessidade de apresentar esse conceito sob uma nova perspectiva.

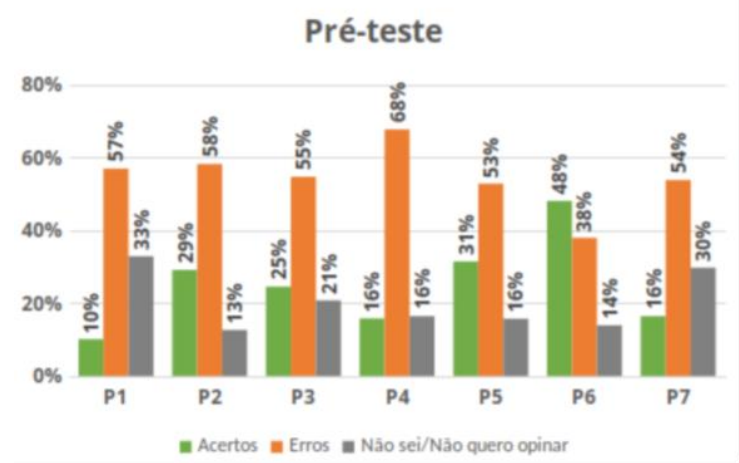

(a)

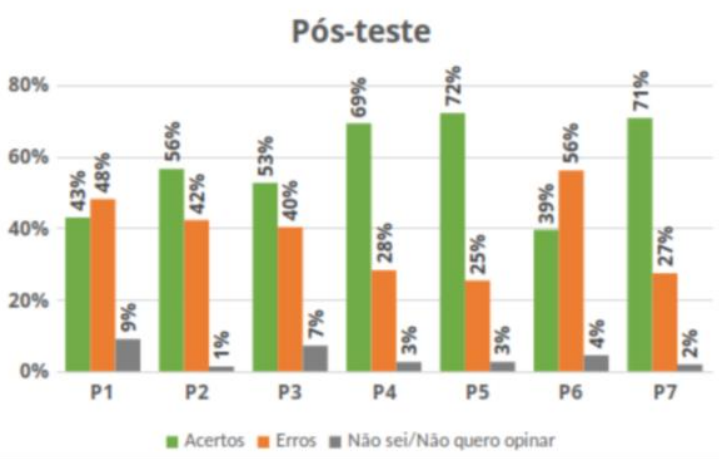

(b)

Figura 6 - Comparativo entre pré-teste e pós-teste. Fonte: Autoria própria.

Salientamos que existiram alguns grupos cujos índices variaram, de forma expressiva, da média dos demais. No entanto, esclarecemos que as possíveis diferenças entre os grupos participantes da intervenção não foram exploradas, na medida em que os(as) pesquisadores(as) não possuíam o controle exato sobre a composição das equipes, que foi desenhada pela própria escola. Portanto, a única característica sabida a esse respeito é que eram grupos mistos em idade e anos escolares, por isso, tal distribuição pode não ter sido equilibrada e tais fatores poderiam ter afetado o resultado, de modo que, em novas ocasiões, essas variáveis serão também controladas para incrementar as análises e estratégias de ação do projeto.

\section{Considerações Finais}

Um dos pontos positivos, implícito ao uso do SRA, foi a participação voluntária e entusiasmada dos(as) estudantes, visto que o anonimato permitiu que os(as) alunos(as) receosos(as) e introvertidos(as) se envolvessem, bem como aqueles que conheciam pouco ou até nada sobre o tema que seria abordado, no caso a AC.

Outrossim, a tecnologia, presente no SRA, possibilitou o diálogo rápido e dinâmico com grupos grandes. Se tal levamento fosse desenvolvido, oralmente, poderia não ter tamanha adesão, ou mesmo se tornar cansativo. Se, de outro lado, utilizássemos por exemplo, um questionário escrito, a recepção, por parte dos(as) adolescentes, poderia ser de uma identificação com a "prova" e com o ensino tradicional, causando talvez certa resistência.

Assim, o fato de tal diálogo ser mediado por um aparato tecnológico, foi bastante positivo e guardou em si uma relação estreita com o assunto da intervenção: tecnologia computacional. Ademais, de toda forma, o levantamento, oralmente, ou por escrito, iria requerer uma equipe para sistematizar as respostas em tempo hábil para que as mesmas pudessem ser utilizadas durante a própria intervenção com os grupos.

Desse modo, outro ponto positivo, foi o fato do SRA oferecer o feedback instantâneo das respostas que permitiu aos(às) condutores(as) da atividade identificar conceitos que não foram compreendidos, adequadamente, pelos(as) participantes, e, de imediato, retomar a explicação sobre eles durante a análise do resultado da própria pergunta, ampliando o alcance e a efetividade da ação educativa em curso. 
Além da melhora, no momento da dinâmica, a identificação de questões que não obtiveram um incremento na taxa de acertos, ou nas quais a diferença foi insignificante, são vistas, dentro do projeto, como uma ferramenta de análise de pontos frágeis da intervenção que necessitam de maior atenção. Assim, o processo educativo pode ser aperfeiçoado, incluindo atividades e abordagens que contemplem de outra forma os assuntos em questão em ações vindouras do projeto.

Uma limitação que merece destaque, acerca do modelo de SRA, utilizado neste trabalho, o TurningPoint $L C D$, refere-se ao fato do software possuir apenas versão compatível com os sistemas operacionais Windows e macOS. Entretanto, diversas escolas possuem instalado, nos computadores escolares, o sistema operacional Linux, podendo esse ser um limitante para sua incorporação em alguns estabelecimentos de ensino, principalmente, os públicos. Salientamos que outros software ${ }^{3}$ podem ser utilizados com o mesmo propósito prescindindo do uso do clicker.

Como trabalhos futuros, estima-se realizar atividades com o uso de outros software e aplicativos que permitam coletar as respostas de públicos diversos, utilizando, por exemplo, os celulares e smartphones dos próprios participantes da atividade. Pretende-se, também, aplicar o uso de SRA com pessoas que possuam menor habilidade relacionada a tecnologias computacionais, como é o caso de pessoas da terceira idade, com o objetivo de apreender sua eficácia.

\section{Referências Bibliográficas}

ALJALOUD, A.; GROMIK, N.; BILLINGSLEY, W.; KWAN, P. Research trends in student response systems: a literature review. International Journal of Learning Technology, v. 10, n. 4, p. 313-325, 2015.

BARRIO, C. M.; MUÑOZ-ORGANERO, M.; SORIANO, J. S. Can gamification improve the benefits of student response systems in learning? An experimental study. IEEE Transactions on Emerging Topics in Computing, v. 4, n. 3, p. 429438, 2015.

BELETI JUNIOR, C. R.; MACEDO, C. A.; ALENCAR, V. H.; SANTIAGO JUNIOR, R. M.; ZÜGE, A. P. Abordagem metodológica para o ensino de Arquitetura de Computadores em ambientes não formais. Revista Brasileira de Informática na Educação, [S.1.], v. 28, p. 335, jun. 2020. ISSN 2317-6121. Disponível em: <https://www.br-ie.org/pub/index.php/rbie/article/view/v28p335/6720>. Acesso em: 04 de jul., 2020.

BRITO, M. A Tecnologia como Recurso Pedagógico na Prática Docente. Anais do Xv Encontro de Iniciação Científica da Uni7, Fortaleza, v. 9, n. 1, p. 1-6, 13 jun. 2019. Disponível em: <https://periodicos.uni7.edu.br/index.php/iniciacaocientifica/article/view/1026>. Acesso em: 05 de maio, 2020.

CALDWELL, Jane E. Clickers in the Large Classroom: current research and bestpractice tips. : Current Research and Best-Practice Tips. Cbe-life Sciences Education, [s.1.], v. 6, n. 1, p. 9-20, mar. 2007. Disponível em: <https://doi.org/10.1187/cbe.06-12-0205>. Acesso em: 13 de maio, 2020.

CARTWRIGHT, B.; FABIAN, S. Researching Student Perceptions of and Experiences with Alternative Learning Technologies - Replacing Traditional Tutorials with i>clicker Tutorials and Online Tutorials. Proceedings of the 9th International Conference on Computer Supported Education (CSEDU 2017), Porto, v. 1, p.

\footnotetext{
3 Como por exemplo: Pingo - disponível em http://trypingo.com/; Direct Poll - disponível em https://www.directpoll.com/; Mentimeter - disponível em https://www.mentimeter.com. V. $18 \mathrm{~N}^{\circ} 1$, julho, 2020 DOI: 
226-233, 2017. Disponível em: <https://doi.org/10.5220/0006253402260233>. Acesso em: 05 de maio, 2020.

DA SILVA, I. C. S.; PRATES, T. S.; RIBEIRO, L. F. S. As Novas Tecnologias e aprendizagem: desafios enfrentados pelo professor na sala de aula. Revista Em Debate, Florianópolis, n. 15, p.107-123, mar. 2017. ISSN 1980-3532. Disponível em: <https://doi.org/10.5007/1980-3532.2016n15p107>. Acesso em: 30 jul. 2019.

DE PAIVA, N. M. N; COSTA, J. S. A influência da tecnologia na infância: desenvolvimento ou ameaça. Psicologia.pt. Porto, 2015. ISSN 1646-6977. Disponível em:<https://www.psicologia.pt/artigos/ver_artigo.php?codigo=A0839>. Acesso em: 25 de ago., 2019.

DȨBIEC, P. Effective learner-centered approach for teaching an introductory digital systems course. IEEE Transactions on Education, v. 61, n. 1, p. 38-45, 2017.

GADOTTI, M. A questão da educação formal/não-formal. In: Institut International Des Droits De L'Enfant (IDE). Droit à l'éducation: solution à tous les problèmes ou problème sans solution? Sion: Institut International des Droits de L'Enfant, p. 111, 2005.

GOHN, M. G. Educação não formal e o educador social: atuação no desenvolvimento de projetos sociais. São Paulo: Cortez, 2010.

GOLDSTEIN, D. S.; WALLIS, P. D. Clickers in the Classroom: Using Classroom Response Systems to Increase Student Learning. Sterling: Stylus Publishing, 2015.

HEASLIP, G.; DONOVAN, P.; CULLEN, J. G. Student response systems and learner engagement in large classes. Active Learning in Higher Education, v. 15, n. 1, p. 11-24, 2014.

HORN, M. B.; STAKER, H. Usando a Inovação Disruptiva para aprimorar a educação. Porto Alegre: Penso, 2015.

MARTYN, M. Clickers in the classroom: An active learning approach. Educause quarterly, v. 30, n. 2, p. 71, 2007.

MEDEIROS, A. F. C.; SOUSA, T. H. J. O.; BEZERRA, E. P.; SILVA, J. C. EASYSRA: Um sistema de resposta à audiência para avaliação contínua. Renote: Revista Novas Tecnologias na Educação, Porto Alegre, v. 10, n. 3, p.1-10, 18 dez. 2012. Disponível em: <https://doi.org/10.22456/1679-1916.36432>. Acesso em: 29 ago. 2019.

MORAES, C. H.; KOHN, K. O impacto das novas tecnologias na sociedade: conceitos e características da Sociedade da Informação e Sociedade Digital. In: III Intercom Júnior - Jornada de Iniciação Científica Comunicação, 2007, Santos. XXX Congresso Brasileiro de Ciências Comunicação. São Paulo: Intercom, 2007. v. 01.

PREMKUMAR, K. Use of student response systems for summative assessments. Creative Education, v. 7, n. 13, p. 1851-1860, 2016.

SANCHES, K. S.; RAMOS, A. de O.; COSTA, F. de J. As tecnologias digitais e a necessidade da formação continuada de professores de Ciências e Biologia para tecnologia: um estudo realizado em uma escola de Belo Horizonte. Revista Tecnologias na Educação, n. 11, 2014.

SILVA, F. R.; CORREIA, S. E. Novas tecnologias e educação: a evolução do processo de ensino e aprendizagem na sociedade contemporânea. Educação e Linguagem, v. 1, n. 1, 2014. p.23-25

SOUSA, T. H. J. O. Impactos na aprendizagem da utilização de sistemas de respostas à audiência. 2013. 113 f. Dissertação (Mestrado em Informática) Universidade Federal da Paraíba, João Pessoa, 2013. 